\title{
Relationship of Education 3.0 Application on The Ability of Andragogy and Pedagogy Prospective Teacher Vocational School
}

\author{
Ahmad Mursyidun Nidhom ${ }^{1}$, Setiadi Cahyono Putra ${ }^{2}$, Hari Putranto3 \\ Jurusan Teknik Elektro, Fakultas Teknik, Universitas Negeri Malang, Indonesia \\ nidhom.ft@um.ac.id, setiadicahyono@gmail.com, hari.putranto.ft@um.ac.id
}

\begin{abstract}
This study aims to reveal the relationship of Education 3.0 (X1) implementation to the ability of andragogy (Y1) and pedagogy (Y2) prospective vocational school teachers. Education 3.0 has a basic concept that education can be modified, adjustable and free conditioned according to the needs of learners, it is very appropriate with improving the ability of andragogy, pedagogy and heutagogy that can be conditioned on the needs of learners. This research uses correlational approach. The samples used were 93 candidate educators taken with simple random sampling technique. The instrument used is nontest (questionnaire) to encompass the variables (Y1) and (Y2) that correlate. Test the hypothesis using correlation test, ujit and test different. The result shows that there is a significant correlation between the application of Education 3.0 to the improvement of the ability of Andragogy and Pedagogy is proved with experimental class average of $\mathbf{8 8 , 0 0}$, meanwhile the control class rate is $\mathbf{7 3 , 7 6}$. $T$ test results also show that tcount is $\mathbf{2 . 6 6}$ with sig. 0.01 and it can be interpreted that there is a significant difference between the experimental class test results with the control class due to the application of Education 3.0 to the ability of Andragogy and Pedagogy Ability.
\end{abstract}

\section{Keywords: Education 3.0; andragogy; pedagogy}

\section{INTRODUCTION}

Education is a self-development of a human being to be able to actualize and enhance the role of life in social life. It is this role that inspires the improvement of methods, strategies or learning approaches. Education also has some improvements to be able to overcome differences with the rapid development of technology today. Learners have started leaving conventional media into interactive multimedia of various types (mobile, augment reality to artificial intelligent). Therefore education also needs to change, one of the changes offered is the version for education, which is believed in every new version will provide new facilities that facilitate learners in learning. The changes or upgrades in question are the development of educational models, such as the development of Education 1.0, Education 2.0 and the latest is Education 3.0 originally inspired by the static web upgrades of $1.0,2.0$ and 3.0 where each version has significant improvements in terms of facilities and usability of website. Education 3.0 has a basic concept that education can be changed, adjustable and free conditioned according to the needs of learners. Unlike Education 1.0 and Education 2.0 the basic concept of learning is facilitated by educators and all learning activities are centered on educators. Education 3.0 brings the basic concept of free learning arranged in patterns (Connectors, Creators, and Constructivists). These three patterns have a continuous relationship in learning, especially in terms of improving the skills of andragogy and pedagogy of Vocational High School educators.

Andragogical abilities are often interpreted as adult learning approaches, but basically the andragogic principle can be applied to all levels of age. The existence of the Internet becomes an important part in the approach of andragogy, learning activities can be done indoors or can be done virtually. Gerstein explained by the Education 3.0 class will be more active with the question and answer session, discussion, reviews, project assignments and learning that carries other interactive concepts [1]. This concepts usually requires customization and personalization, so the learning materials are tailored to meet the more specific and concise student needs. From the description of the background, it is necessary to research to see the relation of Education 3.0 on the ability of andragogy and pedagogy of prospective teachers of Vocational High School, especially in the Department of Electrical Engineering, as a major in Teachers Candidate of Vocational Teachers in Education Study Program of Informatics and Electrical Engineering Education at State University of Malang

\section{LITERATURE REVIEW}

Education 3.0 is an education that can be tailored and freely chosen according to the needs of students. There is a very significant change from the Education 2.0 transition which is still in the form of teacher-facilitated learning (Communication, Contribution, and Collaboration). In the education version 3.0 has turned into a free learning with $3 \mathrm{C}$ concept that is (Connectors, Creators, and Constructivists). This condition automatically changes the role of educator to be a coach or coach and not patronize as in Education 1.0 and 2.0. Educators have more life experience, knowing about the learning process, and have procedural knowledge about how to seek information, identify and use information resources and social networking for non-learning purposes in order to find the information resources is required a computer. 


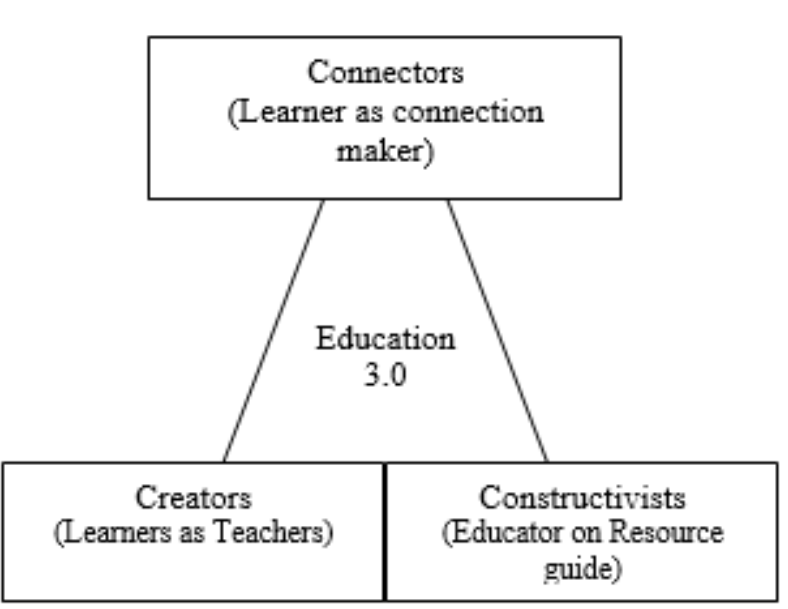

Fig. 1. Education 3.0 Concept

Computers as one form of advanced technology that can be used as a tool in carrying out learning activities. With the help of computer teachers can take advantage of various sources of information around him as a source of learning. In the digital era as it is today it is very necessary to make learning as attractive as possible, as it is conveyed [2] in the digital age of learning must adapt the needs of students without necessarily reducing students' curiosity towards technology. Teachers can use a variety of computer programs to make their learning richer and more interesting as well as more interesting, resulting in increased learning motivation. According to [3] convey that conventional learning needs to be transformed into learning that involves the computer as the media. The lessons referred to in [4] are the ever-changing learning, in this case Education 1.0, Education 2.0 and to date Education 3.0, Fig. 1.

\section{A. The Ability of Andragogy}

Andragogy is a process that provides procedures and resources to help students acquire information and skills. In this model, teachers (facilitators, change-agents, consultants) prepare a set of procedures to engage students in a process that includes (a) building a conducive atmosphere for learning, (b) Creating mechanisms for joint planning, (c) Diagnosing learning needs (d) To formulate the objectives of the program (content) that will meet this need, (e) design the pattern of the learning experience, (f) Conduct learning experiences with appropriate techniques and materials, and (g) Evaluate learning outcomes and analyze learning needs. Andragogical ability also leads to the formation of attitudes toward more flexible and orderly learning [4]. The formation of the attitude is also related to the readiness of students in obtaining information that is usually characterized by understanding the criteria of right and wrong, according to [5] Readiness of students in learning is also influenced aspects of andragogy and heutagogy. Here are the characteristics of andragogy skills. 1). Requires a constructivist learning environment that can provide multiple representations of reality 2). This representation states that the complexity of the real world is very necessary to be imparted to the students 3). Construction of knowledge is emphasized on the reproduction of knowledge between students and teachers 4). Students participate in authentic tasks in the most meaningful context 5). Real world settings provided 6). Reflection of thoughtful experience is recommended to students 7). Collaboration and social negotiation are encouraged among students. 8). There is integration and activation of prior knowledge 9). Learning discovery, collaborative activities, and activities are often integrated into learning and learning activities.

\section{B. The Ability of Pedagogy}

The most traditional concept of pedagogy means a study of how to become a teacher. More specifically, originally the word pedagogy means the way a teacher teaches or the art of teaching. Later the term pedagogy is generally given a broader meaning, which refers to the learning strategy, with a point of emphasis on the style of teachers in teaching. Paedagogi comes from the Greek language (paidagōgeō; país: children and ági: lead) or paedagogia which means association with children. From this word, the term paedagogi is defined as a science and art in teaching children. In subsequent developments the term paedagogi changed into the science and art of teaching.

Pedagogy is also a study of teaching, especially teaching in formal education. In other words, it is the science and art of teaching in school. The ability of pedagogy is also not only related to the way of teaching, but also related to the emotions and attitudes in conveying something [6]. In general pedagogy is a compulsory subject for those who want to become teachers in school. As a broad field of study, pedagogy engages in the study of teaching and learning processes, the management of the darling chamber, the organization of the school and also the teacher-student interaction.

Further issues and complications arising from the use of the term pedagogy are a set of concepts to explain the process. The following three specific issues arise related to pedagogical issues.

- Pedagogy is a purposeful process. In a general sense the term is often used to explain the principles and practice of teaching children.

- Much of the "social pedagogy" work has been used to describe the principles of teaching children and youth. While many authors such as Paulo Freire (1972) have used pedagogical notions referring to work with adults in which is also closely related to teaching children.

- The extent to which pedagogical understanding has been understood and dominant color the learning process in the school context. It is impossible to teach problems only with teachers or students. Discussion about pedagogy is always associated with curriculum, teaching, students, learning media, and the circumstances surrounding it. Even the term pedagogy touches also the dimensions of education in general or the whole order that allows interaction between subjects nuanced teaching and learning, both inside and outside the classroom, at school or out of school.

Thus, traditionally pedagogy is the art of teaching. Effective teachers continue to use alternative learning strategies, since there is no single, universal approach to all teaching materials and situations. According to [7] different Pedagogy learning strategies are used with different combinations for different student groups, which are expected 
to improve learning outcomes. More suitable strategies for teaching certain knowledge and skills differ for each student and context. Teachers as a pilot project in education certainly can sort out effective and efficient learning. According to [8] Master is a future job capable of making change. These changes are related to human resource development and intelligent and reliable student seed preparation in the future.

\section{METHODOLOGY}

In accordance with the background presented, this research uses a quantitative approach with correlational research design. Picture of the relationship of each research variable in detail can be seen in Fig. 2.

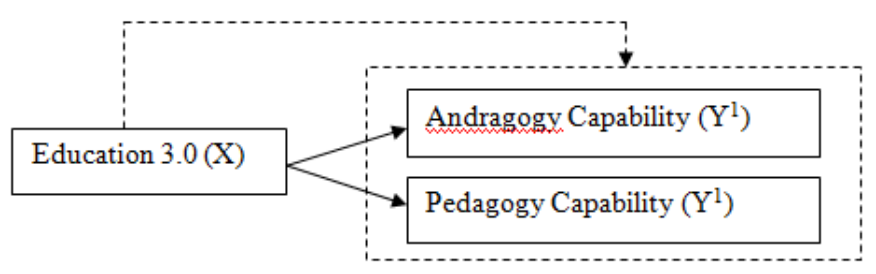

Fig. 2. Research Variable

This research also passes through several stages of research systematically arranged in which there is instrument testing and data analysis followed by discussion, research phase in detail can be seen in Fig. 3 .

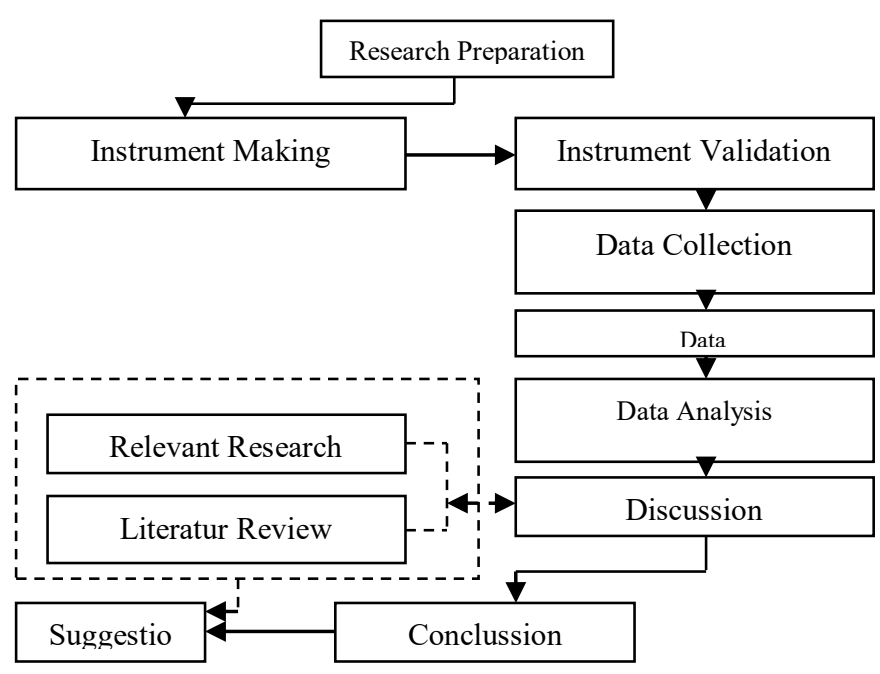

Fig. 3. Research Steps

The population in this study are all students of electrical engineering majors who have the competence of the field of education, namely Informatics Engineering Education (PTI) and Electrical Engineering Education (PTE). As for the sample is the student of PTI and PTE force 2014, the sample selection of force 2014 is assumed that the force of 2014 has completed the PPL (Field Experience practice) and Already completing the course of education. Population distribution data are presented in Table I.
TABLE I.

SAMPLE DISTRIBUTION

\begin{tabular}{|l|l|l|l|}
\hline No & Study Program & Off & Number of Sampling \\
\hline 1 & Informatics Education & A & 12 \\
\hline \multirow{3}{*}{} & & B & 12 \\
& & C & 12 \\
& & D & 12 \\
\hline 2 & Electrical Education & A & 12 \\
& & B & 12 \\
& & C & 11 \\
& & D & 10 \\
\hline & Total & & 93 \\
\hline
\end{tabular}

The sample is determined by Simple Random technique. The Simple Random Sampling technique is used with the aim of providing equal opportunity to all members of the population to be defined as a sample member.

\section{RESULTS AND DISCUSSION}

The results of this study are the questionnaire data of the andragogical ability and pedagogical ability calculated using the interval class length, using the highest score formula minus the lowest score and divided by the number of criteria. Questionnaire retrieval is aimed to see the relation between education 3.0 on the ability of andragogy and pedagogy ability.

\section{A. Education 3.0 relation to the enhancement of} Andragogical Capability

TABLE II. DISTRIBUTION OF ANDRAGOGY CAPABILITIES

\begin{tabular}{|l|l|l|l|l|}
\hline No & Criteria & Interval & Frequency & Percentage \\
\hline 1 & Very High & $52-59$ & 13 & $14,1 \%$ \\
\hline 2 & High & $45-51$ & 39 & $42,0 \%$ \\
\hline 3 & Medium & $38-44$ & 36 & $38,8 \%$ \\
\hline 4 & Low & $31-37$ & 5 & $5,5 \%$ \\
\hline \multicolumn{2}{|l|}{ Total } & 93 & $100 \%$ \\
\hline
\end{tabular}

Based on Table II it can be seen that the ability of Andragogi prospective teachers of SMK Electrical Engineering Department tend to be in the high category as many as 39 respondents $(42.0 \%)$, the rest are in the medium category as many as 36 respondents $(38.8 \%)$, very high category 13 respondents $14.1 \%$ ) and low category as many as 5 respondents $(5.5 \%)$. Based on these data can be concluded Education 3.0 has hunugan to increase the ability of andragogy in the high category.

\section{B. Education 3.0 relation to Pedagogy Capability improvement}

TABLE III. DISTRIBUTION OF PEDAGOGY CAPABILITIES

\begin{tabular}{|l|l|l|l|l|}
\hline No & Criteria & Interval & Frequency & Percentage \\
\hline 1 & Very High & $51-58$ & 10 & $10,8 \%$ \\
\hline 2 & High & $44-50$ & 33 & $35,7 \%$ \\
\hline 3 & Medium & $37-43$ & 42 & $45,3 \%$ \\
\hline 4 & Low & $30-36$ & 8 & $8,7 \%$ \\
\hline \multicolumn{2}{|l}{ Total } & 93 & $100 \%$ \\
\hline
\end{tabular}


Based on Table III it can be seen that pedagogical ability of candidate of vocational teacher of Electrical Engineering Department in medium category is 42 respondents $(45,3 \%)$, the rest are in high category 33 respondents $(35,7 \%)$, very high category 10 respondent $(10.8 \%)$ and low category of 8 respondents $(8.7 \%)$. Based on these data can be concluded Education 3.0 has a relationship to the improvement of pedagogical skills in the medium category.

\section{Effectiveness of Education 3.0 Against Andragogical Ability and Pedagogic Capabilities}

After conducting the next questionnaire test conducted effectiveness of education 3.0 with the ability andragogy and pedagogy with quasi-experimental methods. In this advanced method, a control class and an experimental class are determined.

TABLE IV. SUMMARY OF INITIAL VALUE TEST RESULTS

\begin{tabular}{|l|l|l|l|l|}
\hline \multicolumn{5}{|l}{ t-test for Equality of Means } \\
\hline $\mathrm{t}$ & $\mathrm{df}$ & Sig. (2-tailed) & Mean Difference & Std. Error Difference \\
\hline 1.173 & 56 & .247 & 2.690 & 2.296 \\
\hline 1.173 & 55.587 & .247 & 2.690 & 2.296 \\
\hline
\end{tabular}

This initial capability test data is obtained from the initial ability score before being treated with Education 3.0. This initial capability test data is performed to determine the pre-test hypothesis test according to the data to be analyzed.

Summary of Table IV shows that tcount is 1.173 with sig. 0.247 and it can be interpreted that there is no significant difference between the initial experimental class test results and the control class. Furthermore, data analysis was done by ttest.

\section{TABLE V. SUMMARY OF FINAL VALUE TEST RESULTS}

\begin{tabular}{|l|l|l|l|l|}
\hline \multicolumn{2}{|l}{ t-test for Equality of Means } \\
\hline $\mathrm{t}$ & $\mathrm{df}$ & Sig. (2-tailed) & Mean Difference & Std. Error Difference \\
\hline 2.666 & 56 & .010 & 5.241 & 1.966 \\
\hline 2.666 & 53.457 & .010 & 5.241 & 1.966 \\
\hline
\end{tabular}

This final capability test data is obtained from the final ability score after being treated with education 3.0 learning. This initial capability test data is performed to determine the pre-test hypothesis test according to the data to be analyzed, Table V.

Summary of the above results shows that tcount is 2.66 with sig. 0.01 and it can be interpreted that there is a significant difference between the test results of the initial ability of the experimental class and the control class.

\section{Description of the Effectiveness of Education 3.0 on the ability of Andragogy and Pedagogy}

The results of t-test data with the help of SPSS 20.0 for Windows show a significant difference. In the experimental class, the analysis with the average technique obtained the result that the average value of the final ability of the experimental group that received treatment amounted to 88.00. The mean of control class is 73,76 . From the calculation that means the decision obtained is $\mathrm{H} 0$ rejected so that it concluded that there is a significant difference between the test results of experimental class end capability and control. From the description above it can be seen that the ability andragogy and ability of experimental class pedagogy with the application of education 3.0 differed significantly with the control class that did not use education 3.0 approach.

The results of different test calculations of effectiveness analysis showed that the students in the experimental group had values above the students in the control group. In addition, the mean value of end-ability in the experimental group was higher than the control group in the learning process. Thus there is a significant difference in the application of education 3.0 approach. It is also supported by the calculation so that $\mathrm{Ha}$ accepted that there is a significant difference in the final test results of the control class and the experimental class.

\section{CONCLUSION}

Based on the findings and discussion can be drawn the following conclusions. First, Education 3.0 has a correlation to the enhancement of andragogical abilities in the high category, as evidenced by 39 respondents $(42.0 \%)$, strongly agree if Education 3.0 can improve andragogy ability, the rest are in the medium category of 36 respondents (38.8\%), very high category 13 respondents $(14.1 \%)$ and low category as many as 5 respondents $(5.5 \%)$. This is in accordance with the study [9] which mentions Education 3.0 is a learning approach that gives the impression of comfortable to students, students are given the opportunity to do the desired during the learning phase. Second. Education 3.0 has relationship to pedagogy improvement, but in moderate category, it is proved by 42 respondents $(45,3 \%)$, the rest are in high category 33 respondents $(35,7 \%)$, very high category 10 respondents $(10$, $8 \%$ ) and low category of 8 respondents $(8.7 \%)$. Third Test of Effectiveness of Education 3.0 with the ability of Andragogy and Pedagogy Candidate of Vocational High School teachers also experienced a significant increase, it is proved by different thitung with the preliminary and final test, so it can be concluded the application of Education 3.0 approach gives an increase to pedagogy and andragogy ability. Fourth. In the experimental class, the analysis with the average technique obtained the result that the average value of the final ability of the experimental group that received treatment amounted to 88.00. The mean of control class is 73,76 . From the results of the calculation can be concluded that $\mathrm{H} 0$ rejected so that it concluded that there is a significant difference between the end of experimental class test results and control. From the description above it can be seen that the ability andragogy and ability of experimental class pedagogy with the application of education 3.0 differed significantly with the control class that did not use education 3.0 approach.

\section{REFERENCES}

[1] J. Gerstein, "Moving from Education 1.0 Through Education 2.0 Towards Education 3.0.," Exp. Self-Determined Learn., pp. 83-98, 2014.

[2] [2] S. Wheeler, Learning with "e"s: educational theory and practice in the digital age. Wales: Crown House Publishing, 2015. 
[3] R. A. A. O. K. Rahmat and K. Osman, "From Traditional to SelfRegulated Learners: UKM Journey Towards Education 3.0," Procedia Soc. Behav. Sci., vol. 59, pp. 2-8, 2012.

[4] Rismiyanto, M. Saleh, J. Mujiyanto, and A. Shofwan, "Andragogy and pedagogy: Learning method orientations for Efl adult learners," Asian J., vol. 5, no. 2, pp. 256-265, 2017.

[5] A. M. Nidhom, A. S. KH, and D. A. Sudjimat, "Hubungan Kesiapan Belajar, Lama Pembelajaran, Kesesuaian Tempat dan Partisipasi DU/DI dengan Hasil Prakerin Peserta Didik Kompetensi Keahlian TKJ di SMK Kota Batu," Innov. Vocat. Technol. Educ., vol. 11, no. 1, pp. 1-14, 2015.

[6] R. García-Pérez, J.-M. Santos-Delgado, and O. Buzón-García, "Virtual empathy as digital competence in education 3.0," Int. J. Educ. Technol. High. Educ., vol. 13, no. 1, p. 30, Jul. 2016.
[7] T. Anderson and J. Dron, "Three generations of distance education pedagogy," Int. Rev. Res. Open Distrib. Learn., vol. 12, no. 3, pp. 8097, 2010.

[8] J. R. Thompson, W. M. Christensen, and M. C. Wittmann, "Preparing future teachers to anticipate student difficulties in physics in a graduatelevel course in physics, pedagogy, and education research," Phys. Rev. Spec. Top. - Phys. Educ. Res., vol. 7, no. 1, pp. 1-11, 2011.

[9] J. Wang, "Education 3.0: Effect learning style and method of instruction on user satisfaction," Eur. Acad. Res., vol. 1, no. 5, pp. 755-769, 2013. 